\title{
Characteristics of stereotactic radiotherapy clinical trials registered on ClinicalTrials.gov
}

\author{
Xin Zhang, Ding-Yi Yang, Can Wang, Luo Huang \\ Department of Radiation Oncology, Chongqing University Cancer Hospital, Chongqing, China \\ Contributions: (I) Conception and design: X Zhang; (II) Administrative support: L Huang; (III) Provision of study materials or patients: DY Yang; (IV) \\ Collection and assembly of data: C Wang; (V) Data analysis and interpretation: X Zhang; (VI) Manuscript writing: All authors; (VII) Final approval \\ of manuscript: All authors. \\ Correspondence to: Luo Huang. Chongqing University Cancer Hospital, No. 181 Hanyu Road, Shapingba District, Chongqing 400030, China. \\ Email: 252665101@qq.com.
}

Background: We aim to analyze the characteristics of stereotactic radiotherapy trials registered on ClinicalTrials.gov, and to compare completed and stopped early trials to identify predictors of trial failure.

Methods: All interventional stereotactic radiotherapy trials registered on ClinicalTrials.gov before Dec 31, 2019 were downloaded. Trial characteristics over time and between different regions were compared by Chisquare test. Binary logistic regression was used to explore characteristics associated with trials stopped early.

Results: A total of 760 trials were included. A higher proportion of trials were about lung cancer (20.4\%), prostate cancer (14.7\%) and central nervous system (14.6\%). Most trials were phase1 and/or 2 trials (63.0\%), single group (62.4\%), nonrandomized (71.7\%), open-label $(95.0 \%)$ and single center $(75.8 \%)$. The median sample size was $40(0-1,716)$. Only $15.1 \%$ and $13.5 \%$ were funded by industry and National Institutes of Health (NIH), respectively. 15.4\% stopped early with status includes "suspended", "terminated" and "withdrawn". Of the 113 "completed" trials, only 28 were published on PubMed. Compared with 2010 to 2014, trials from 2015 to 2019 were more likely to be randomized (20.0\% vs. 34.4\%; P=0.001), with 2 study arms (27.1\% vs. $42.1 \% ; \mathrm{P}=0.002)$, industry-funded $(11.0 \%$ vs. $19.1 \% ; \mathrm{P}=0.028)$ and conducted in Asia $(7.6 \%$ to $15.8 \% ; \mathrm{P}=0.002)$. Trials from North America were more oriented toward phase 1 research $(24.4 \%$ vs. $6.1 \%$ for Europe and $6.5 \%$ for Asia, $\mathrm{P}<0.001)$, nonrandomized $(77.7 \%$ vs. $56.8 \%$ for Europe and $64.1 \%$ for Asia, $\mathrm{P}<0.001)$. Trials from Asia were more likely to have recruiting status (56.5\% vs. $45.5 \%$ for Europe and $43.6 \%$ for North America, $\mathrm{P}<0.001)$. Multivariate regression analysis showed that randomized (OR 8.090, $\mathrm{P}=0.001)$, and enrollment patients $\leq 50(\mathrm{OR} 3.813, \mathrm{P}<0.001)$ were associated with trials stopped early.

Conclusions: Stereotactic radiotherapy trials are predominantly early-phase, small, single arm, nonrandomized and open label. Trials with randomized allocation or enrollment patients $\leq 50$ were more likely to stop early.

Keywords: Stereotactic radiotherapy (SRS); clinical trials; characteristics

Submitted Jul 05, 2021. Accepted for publication Sep 14, 2021.

doi: $10.21037 /$ tcr-21-1189

View this article at: https://dx.doi.org/10.21037/tcr-21-1189

\section{Introduction}

In recent years, stereotactic radiotherapy has become more popular in clinical practice of various cancer, due to its satisfactory efficacy and relatively less side effects (1). Stereotactic radiotherapy is defined as a radiation therapy that use high doses per fraction in one to five fractions with highly conformal techniques $(2,3)$. It is a general term that includes stereotactic radiosurgery (SRS) and stereotactic body radiation therapy (SBRT). SRS uses a single fraction delivered with precision similarly to surgery. While SBRT, also known as stereotactic ablative radiotherapy (SABR), uses high doses per fraction for a maximum of 5 fractions with ablative intent 
on extracranial lesions (4). However, the data related to contemporary trials evaluating stereotactic radiotherapy and their ability to advance clinical care do not yet exist.

ClinicalTrials.gov is a registry of clinical trials that was mandated by Congress and implemented in 2000 by the National Library of Medicine. In 2004, the International Committee of Medical Journal Editors announced a policy of registration of clinical trials as a prerequisite for publication (5). Furthermore, in 2007, the Food and Drug Administration Amendment Act expanded legal requirements to register trials, as well as record key data elements (6). ClinicalTrials.gov is the largest of the international registries for clinical trials and represents a unique resource to explore the research enterprise worldwide. Currently, ClinicalTrials.gov contains detailed information on more than 380,000 clinical research studies conducted in 299 countries (7). However, previous studies have found that a large amount of clinical trials are failing to complete, and numerous trials are not published for several years after completion (8). Failed clinical trials resulting in wasting time, effort and resources, also bring risks to trial participation (9).

In this study, we aimed to describe the fundamental characteristics of interventional stereotactic radiotherapy studies registered on ClinicalTrials.gov before Dec 31, 2019. We also described the changes of characteristics of stereotactic radiotherapy trials over time, and compared characteristics from different regions. Furthermore, we investigated trial characteristics that may be associated with trial stopped early, to better inform the design of future trials.

\section{Methods}

\section{Data collection}

Clinicaltrials.gov was queried for the topic "SBRT," "Stereotactic Body Radiation Therapy", "SABR", "Stereotactic Ablative Radiotherapy", "SRS" and "Stereotactic Radiosurgery" in the "other terms". All studies registered before Dec 31, 2019 were downloaded and set into a relational database of the Aggregate Analysis of ClinicalTrials.gov for aggregate analysis. Only "interventional trials" and "primary purpose was treatment" were included.

Stereotactic radiotherapy trials were examined on 11 dimensions: cancer type; phase of trial; number of treatment arms; randomization; masking; sample size; age of participants; funding source; location of trial sites; recruiting status; study start date.

\section{Definitions}

Stereotactic radiotherapy trials that involved 2 or more cancer types were grouped into a "multiple" category. The metastases cancer, such as "brain metastases" or "bone metastases", were grouped into homologous location of tumor like "Central Nervous System" or "Bone".

When the interventional model was single group assignment or the number of treatment arms was "1", the allocation methods (if missing) were designated as nonrandomized and the masking (if missing) was designated as open label. Funding sources were classified into National Institutes of Health (NIH), industry, and other. "NIH and other" was assigned as NIH. "Industry and other" was assigned as industry.

\section{Statistical analysis}

Descriptive statistics were used to investigate the percentage distribution of all the items of the stereotactic radiotherapy trials. Characteristics between the 2 periods of time and between different regions were compared by Chi-square test. A study status including "suspended", "terminated" or "withdrawn" was defined as stopped early. In order to investigate predictors associated with trial stopped early, Chi-square test was used to compare characteristics of completed and stopped early trials. Variables with $\mathrm{P}<0.05$ in univariable analysis were further analyzed by multivariable analysis using binary logistic regression. All statistical tests were 2 -sided with statistical significance when $\mathrm{P}<0.05$. SPSS version 22.0 (IBM Corp) was used for all statistical analyses.

\section{Results}

We retrieved 897 trials from ClinicalTrials.gov before Dec 31, 2019 by restricting topic, 760 interventional stereotactic radiotherapy trials were finally selected for analysis (Figure 1). The first interventional stereotactic radiotherapy trial registered on Nov 1,1994. And then, the number increased gradually from 2004 to 2019 (Figure 2). A higher proportion of stereotactic radiotherapy trials were conducted for patients with lung cancer $(20.4 \%)$, prostate cancer (14.7\%), central nervous system (14.6\%), and liver cancer (10.4\%) (Figure 3). The "others" included esophageal cancer, sarcoma, lymphoma, skin cancer, thymoma and so on.

The characteristics of interventional stereotactic radiotherapy trials were described in the Table 1. Most 


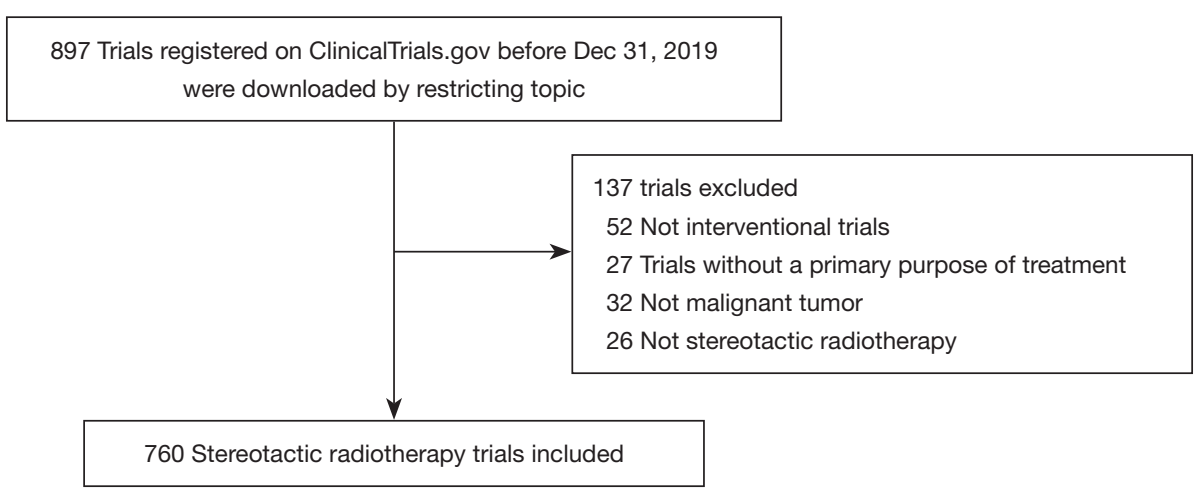

Figure 1 Flowchart for inclusion of stereotactic radiotherapy clinical trials registered on ClinicalTrials.gov.

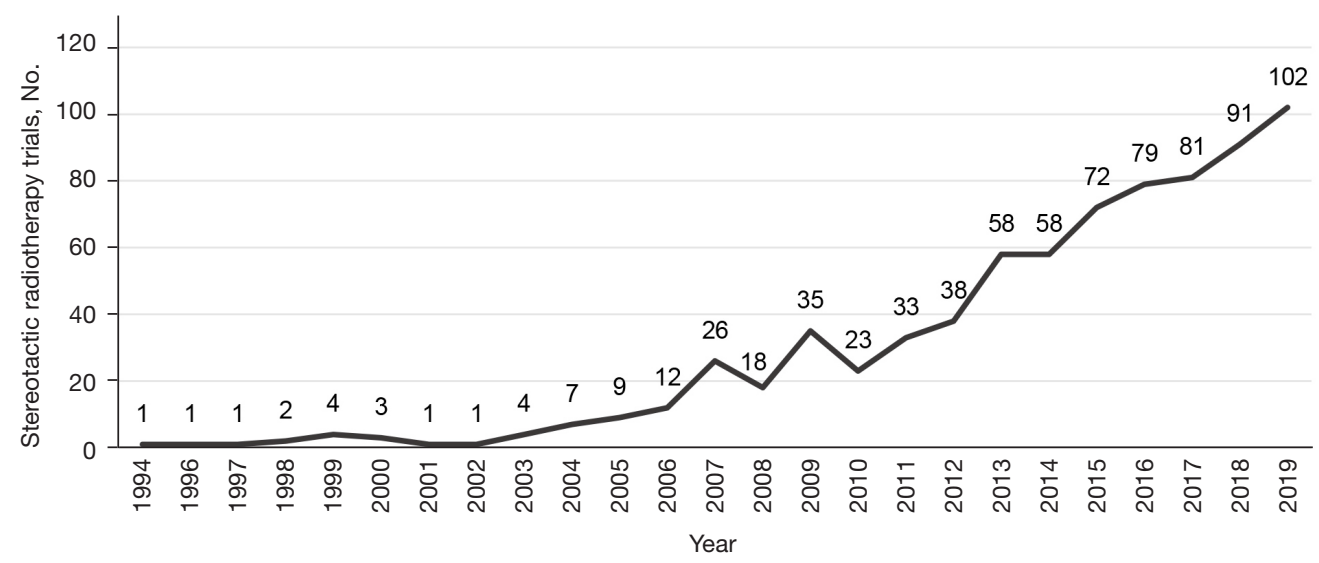

Figure 2 Number of Stereotactic Radiotherapy Trials Registered on ClinicalTrials.gov per Year before Dec 31, 2019.

(63.0\%) were phase1 and /or 2 trials. In all, $474(62.4 \%)$ trials were single group interventional trials, 545 (71.7\%) were reported to be nonrandomized, and $722(95.0 \%)$ were open-label. Four hundred and eighty-one $(63.3 \%)$ of these trials had an anticipated enrollment fewer than 50 and 8 $(1.1 \%)$ had an anticipated enrollment more than 500 . The median trial sample size was $40(0-1,716)$. Almost all trials (97.4\%) excluded children (age $<18$ years), and $9(1.2 \%)$ excluded elderly (age $>65$ years). Only $115(15.1 \%$ ) and 103 $(13.5 \%)$ were funded by industry and NIH, respectively. There were 516 (67.9\%) trials conducted in North America. The majority of trials $(75.8 \%)$ were single center trials. About a half (46.1\%) of trials were recruiting, while 118 (15.4\%) stopped early with status includes "suspended", "terminated" or "withdrawn". Overall 113 (14.9\%) trials were listed as "completed", only 28 trials of them were published on PubMed.

According to study content, stereotactic radiotherapy trials were divided into six categories and the proportions were calculated: (I) added stereotactic radiotherapy to the standard care, 481 (63.3\%); (II) compared any treatment regimens with or without stereotactic radiotherapy, 77 (10.1\%); (III) investigated novel stereotactic radiotherapy regimes, such as doses or fractionations, 64 (8.4\%); (IV) compared stereotactic radiotherapy with other radiotherapy regimens, such as conventional or hypofractionation, 46 $(6.1 \%)$; (V) compared stereotactic radiotherapy with other non-radiotherapy treatments, such as surgery, $52(6.8 \%)$; (VI) different combinations of stereotactic radiotherapy with various treatment modalities, 40 (5.3\%). Notably, $119(15.7 \%)$ trials were regard to stereotactic radiotherapy combined with immunotherapy including immune checkpoint inhibitors.

\section{Chronological shifts of characteristics of stereotactic radiotherapy trials}

The number of stereotactic radiotherapy trials registered 


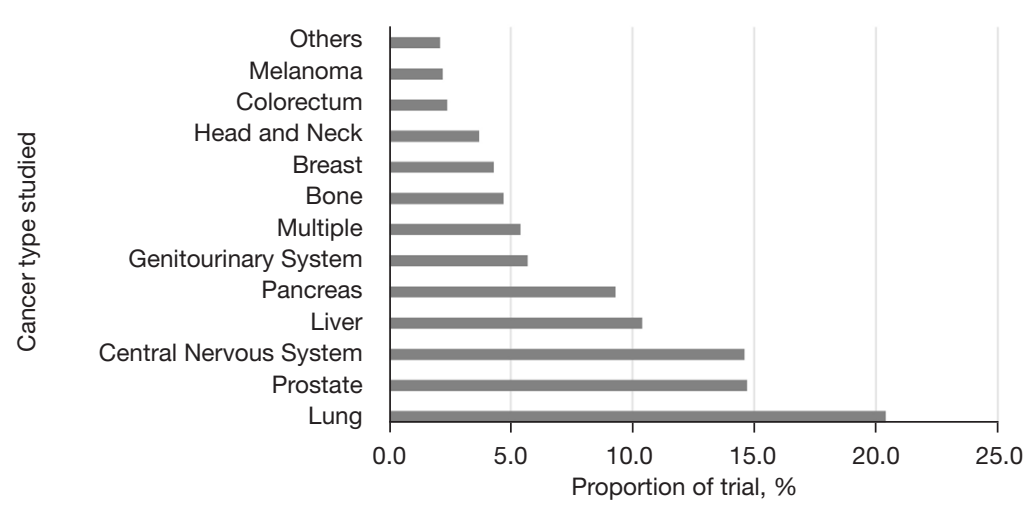

Figure 3 Cancer Types of Stereotactic Radiotherapy Trials Registered on ClinicalTrials.gov.

Table 1 Characteristics of stereotactic radiotherapy trials registered on ClinicalTrials.gov

\begin{tabular}{|c|c|}
\hline Characteristic & No. (\%), $n=760$ \\
\hline \multicolumn{2}{|l|}{ Phase } \\
\hline 1 & $144(18.9)$ \\
\hline $1-2$ & $72(9.5)$ \\
\hline 2 & $263(34.6)$ \\
\hline $2-3$ & $10(1.3)$ \\
\hline 3 & $59(7.8)$ \\
\hline 4 & $5(0.7)$ \\
\hline Not reported & 207 (27.2) \\
\hline \multicolumn{2}{|l|}{ No. of study arms } \\
\hline 1 & $474(62.4)$ \\
\hline 2 & $266(35.0)$ \\
\hline$\geq 3$ & $13(1.7)$ \\
\hline Not reported & $7(0.9)$ \\
\hline \multicolumn{2}{|l|}{ Allocation } \\
\hline Randomized & $210(27.6)$ \\
\hline Nonrandomized & $545(71.7)$ \\
\hline Not reported & $5(0.7)$ \\
\hline \multicolumn{2}{|l|}{ Blinding } \\
\hline Open label & $722(95.0)$ \\
\hline Blind & $21(2.8)$ \\
\hline Not reported & $17(2.2)$ \\
\hline \multicolumn{2}{|c|}{ Enrollment No. of patients } \\
\hline$\leq 50$ & $481(63.3)$ \\
\hline $51-100$ & $137(18.0)$ \\
\hline$\geq 101$ & $142(18.7)$ \\
\hline
\end{tabular}

Table 1 (continued)

\begin{tabular}{|c|c|}
\hline Characteristic & No. (\%), $n=760$ \\
\hline Excludes children (age <18 y) & $740(97.4)$ \\
\hline Excludes elderly (age >65 y) & $9(1.2)$ \\
\hline \multicolumn{2}{|l|}{ Funding source } \\
\hline Industry & $115(15.1)$ \\
\hline $\mathrm{NIH}$ & $103(13.6)$ \\
\hline Industry and $\mathrm{NIH}$ & $4(0.5)$ \\
\hline Other & $538(70.8)$ \\
\hline \multicolumn{2}{|l|}{ No. of geographic regions } \\
\hline 1 & $576(75.8)$ \\
\hline $2-10$ & $149(19.6)$ \\
\hline$\geq 11$ & $35(4.6)$ \\
\hline \multicolumn{2}{|l|}{ Region } \\
\hline North America & $516(67.9)$ \\
\hline Europe & $132(17.4)$ \\
\hline Asia & $92(12.1)$ \\
\hline Other & $20(2.6)$ \\
\hline \multicolumn{2}{|l|}{ Recruitment status } \\
\hline Recruiting & $350(46.1)$ \\
\hline Not yet recruiting & $117(15.4)$ \\
\hline Stopped early & $118(15.5)$ \\
\hline Completed & $113(14.9)$ \\
\hline Not reported & $62(8.2)$ \\
\hline
\end{tabular}

"Stopped early" includes trials that were "suspended", "terminated" or "withdrawn" in the database. NIH, National Institutes of Health.

Table 1 (continued) 
before 2009 was 125 , only accounted for $16.4 \%$ of all trials. So we just compared the characteristics of stereotactic radiotherapy trials between the 2 periods (2010-2014 and 2015-2019) (Table 2). The number of trials submitted for registration increased from 210 to 425 during the 2 periods. Compared with trials from 2010 to 2014, a higher proportion of trials from 2015 to 2019 were randomized (20.0\% vs. $34.4 \% ; \mathrm{P}=0.001)$ and with 2 study arms $(27.1 \%$ vs. $42.1 \% ; \mathrm{P}=0.002)$. Moreover, the proportion of trials with a sample size of more than 100 patients increased from $12.9 \%$ to $22.6 \%$ between the 2 time periods $(\mathrm{P}=0.002)$.

The proportion of trials reporting an industry lead funded increased from $11.0 \%$ to $19.1 \%(\mathrm{P}=0.028)$. The proportion of trials study site in North America decreased from 74.8\% to $60.2 \%(\mathrm{P}=0.002)$, whereas an increase was observed in the proportion of trials in Asia ( $7.6 \%$ to $15.8 \%$ ) during the 2 periods. Moreover, Trials from 2015 to 2019 were more likely to have recruiting status $(68.5 \%$ vs. $26.7 \%$; $\mathrm{P}<0.001)$ and were less likely to report stopped early $(9.4 \% v s .20 .5 \%$; $\mathrm{P}<0.001)$ than trials from 2010 to 2014 . Other characteristics remained unchanged substantially between the 2 periods.

\section{Characteristics of stereotactic radiotherapy trial from different regions}

Table 3 presents the comparison of characteristics of stereotactic radiotherapy trials between North America $(\mathrm{n}=516)$, Europe $(\mathrm{n}=132)$ and Asia $(\mathrm{n}=92)$. With respect to phases, trials from North America were more oriented toward phase 1 research $(24.4 \%$ vs. $6.1 \%$ for Europe and $6.5 \%$ for Asia, $\mathrm{P}<0.001)$. Moreover, Trials from North America were more likely to be nonrandomized (77.7\% vs. $56.8 \%$ for Europe and $64.1 \%$ for Asia, $\mathrm{P}<0.001$ ), open label (96.9\% vs. $94.7 \%$ for Europe and $88.0 \%$ for Asia, $\mathrm{P}=0.001$ ), and with 1 study arm (67.8\% vs. $50.0 \%$ for Europe and $2.2 \%$ for Asia, $\mathrm{P}=0.003)$.

The proportion of trials from North America with a sample size of more than 100 patients was significantly less than Europe (14.2\% vs. 28.0\%) and Asia (14.2\% vs. 31.5\%; $\mathrm{P}<0.001)$. As for recruitment status, trials from Asia were more likely to have recruiting status $(56.5 \%$ vs. $45.5 \%$ for Europe and $43.6 \%$ for North America, $\mathrm{P}<0.001$ ), and less likely to report stopped early ( $8.7 \%$ vs. $12.1 \%$ for Europe and $16.7 \%$ for North America, $\mathrm{P}<0.001)$.

Differences in the funding source were also apparent. Eighteen percent of trials from North America were funded by industry, which was significantly higher than that from Europe $(11.4 \%)$ and Asia $(7.6 \%)(\mathrm{P}<0.001)$. There were no
$\mathrm{NIH}$-funded trials in Asia.

Trials from Asia were more likely conducted in single center than Europe (84.8\% vs. 65.2\%) and North America (84.8\% vs. $77.1 \% ; \mathrm{P}=0.012$ ).

\section{Characteristics associated with stereotactic radiotherapy trial stopped early}

Table 4 showed the univariate analysis of characteristics between completed $(n=113)$ and stopped early $(n=118)$ stereotactic radiotherapy trials. Randomized trials were more frequently stopped early compared with nonrandomized or not reported trials $(\mathrm{P}=0.010)$. And trials with enrollment patients $\leq 50$ were more frequently stopped early compared with patients $>50(\mathrm{P}<0.001)$. Further multivariate regression analysis was performed (Table 5). Randomized (OR 8.090, 95\% CI: 3.095-21.145, P=0.001), and enrollment patients $\leq 50$ (OR 3.813, 95\% CI: 1.759 $8.267, \mathrm{P}<0.001)$ were associated with trials stopped early.

\section{Discussion}

To our knowledge, this analysis is the first comprehensive study to assess the characteristics of stereotactic radiotherapy trials registered on ClinicalTrials.gov, and to investigate trial characteristics that may be associated with trial stopped early. The study helps to better understand the current situation of stereotactic radiotherapy trials and provides basis for future development.

With the development of radiobiology and new advanced technologies, stereotactic radiotherapy is used more frequently. Stereotactic radiotherapy can deliver high doses of radiation with great precision and low damage to the surrounding healthy tissue, and it is very feasible and applicable for oligo progression and oligo metastatic disease (9). SABR-COMET trial showed that standard of care plus SBRT to all metastatic sites improved OS and PFS (10). Different fractionation schemes are adopted based on the characteristics, location and size of tumor. However, the optimal fractionation scheme, dose limits for organs at risk, long term adverse reactions are still not clear. Therefore, more well-designed clinical trials are needed to provide evidence for better defines the clinical implementation of stereotactic radiotherapy in the future.

Stereotactic radiotherapy broadened its areas from brain metastases to early-stage lung cancer, prostate cancer and hepatocellular cancer (11-13). The number of stereotactic radiotherapy trials increased gradually during the last 
Table 2 Trend changes in characteristics of stereotactic radiotherapy trials registered on ClinicalTrials.gov Between 2010-2014 and 2015-2019

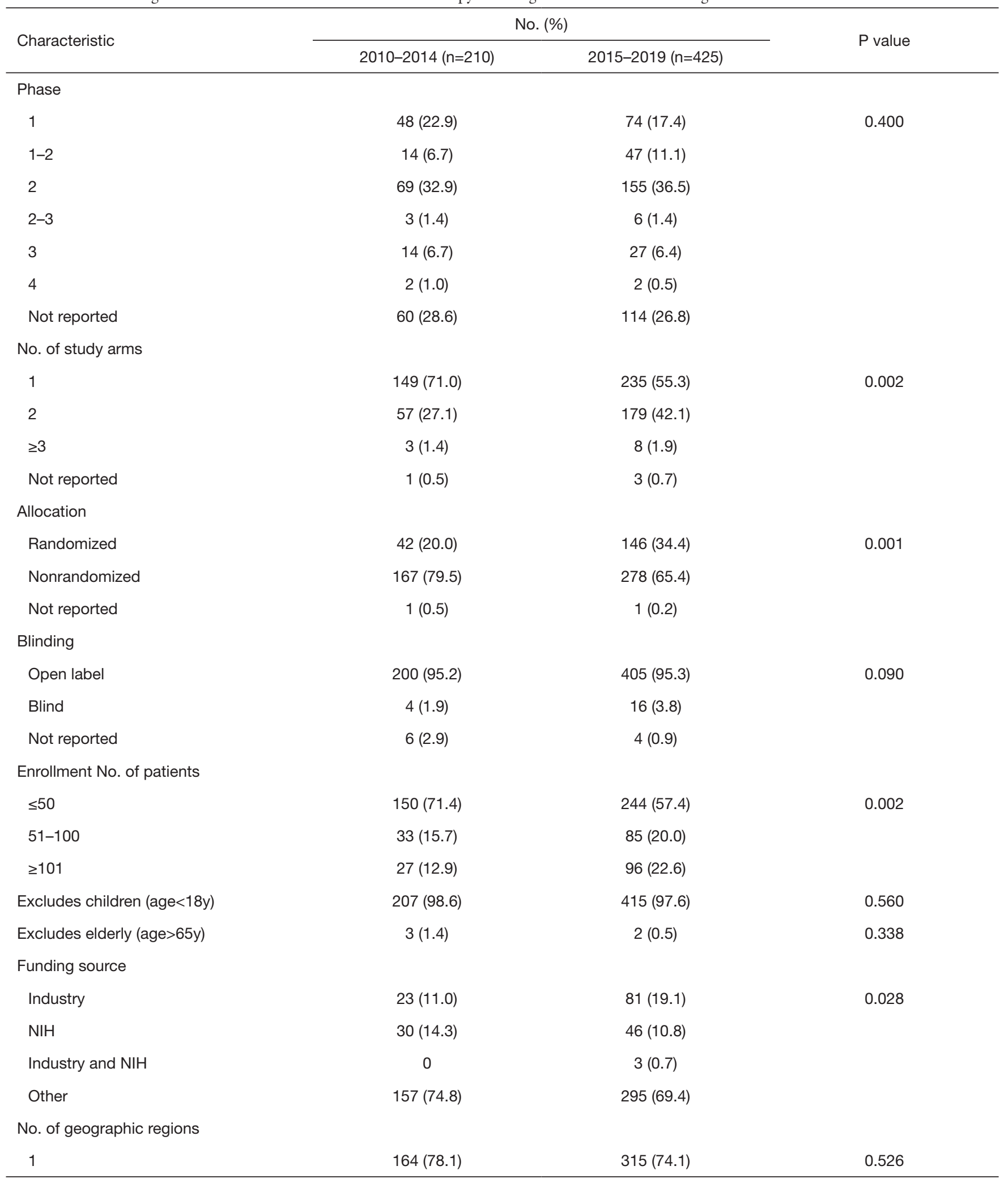

Table 2 (continued) 
Table 2 (continued)

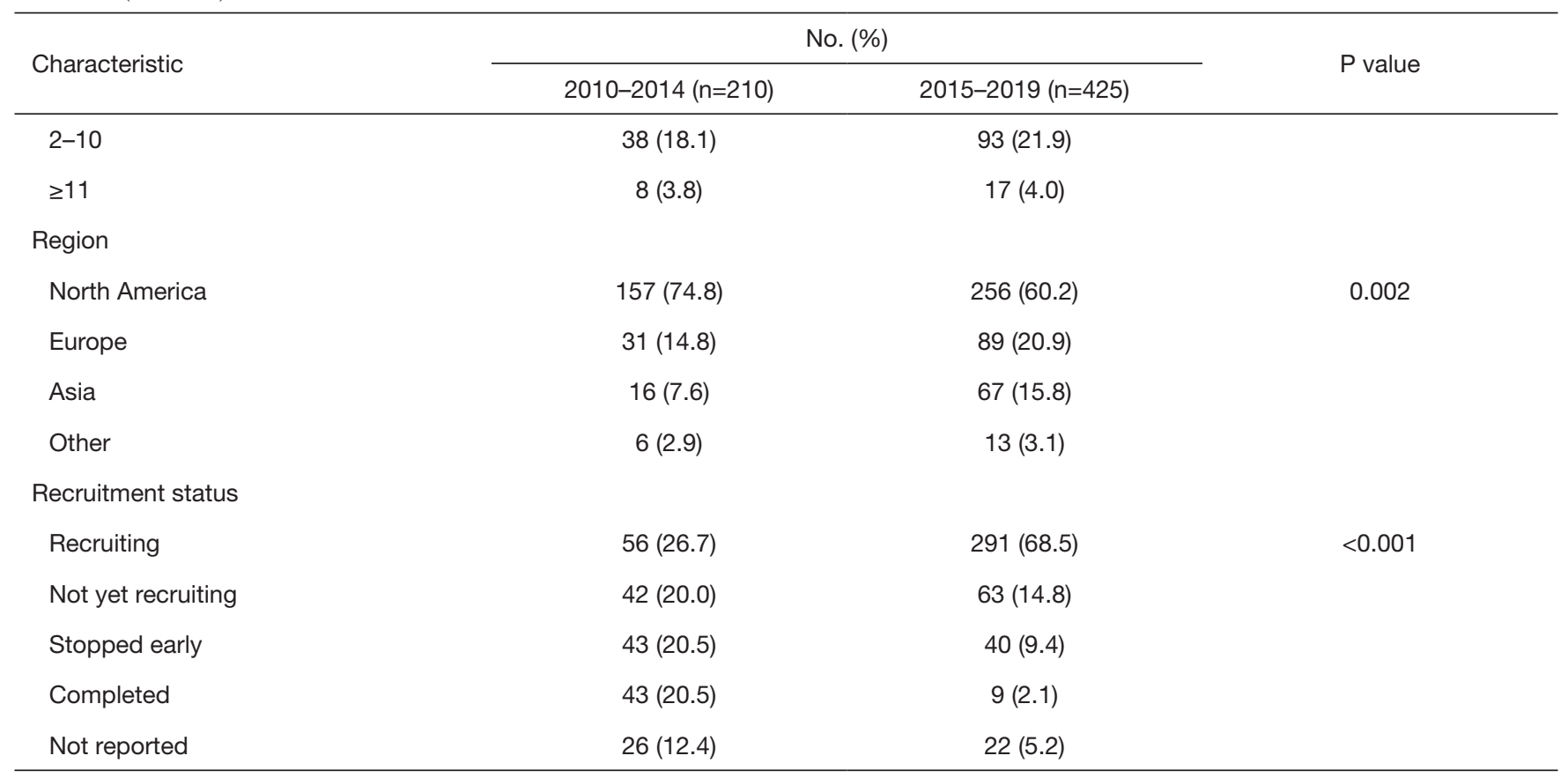

$\mathrm{NIH}$, National Institutes of Health.

Table 3 Comparison of characteristics of stereotactic radiotherapy trial from North America, Europe and Asia

\begin{tabular}{|c|c|c|c|c|}
\hline Characteristic & \multicolumn{3}{|c|}{ No. (\%) } & $P$ value \\
\hline \multicolumn{5}{|l|}{ Phase } \\
\hline $1-2$ & $56(10.9)$ & $14(10.6)$ & $1(1.1)$ & \multirow{5}{*}{$<0.001$} \\
\hline 2 & $155(30.0)$ & $50(37.9)$ & $47(51.1)$ & \\
\hline 3 & $30(5.8)$ & $14(10.6)$ & $13(14.1)$ & \\
\hline 4 & $5(1.0)$ & $0(0.0)$ & $0(0.0)$ & \\
\hline Not reported & 141 (27.3) & $42(31.8)$ & $23(25.0)$ & \\
\hline \multicolumn{5}{|l|}{ No. of study arms } \\
\hline Not reported & $4(0.8)$ & $1(0.8)$ & $2(2.2)$ & 0.003 \\
\hline \multicolumn{5}{|l|}{ Allocation } \\
\hline Randomized & $111(21.5)$ & $57(43.2)$ & $32(34.8)$ & \multirow[t]{3}{*}{$<0.001$} \\
\hline Nonrandomized & $401(77.7)$ & $75(56.8)$ & $59(64.1)$ & \\
\hline Not reported & $4(0.8)$ & $0(0.0)$ & $1(1.1)$ & \\
\hline
\end{tabular}

Table 3 (continued) 
Table 3 (continued)

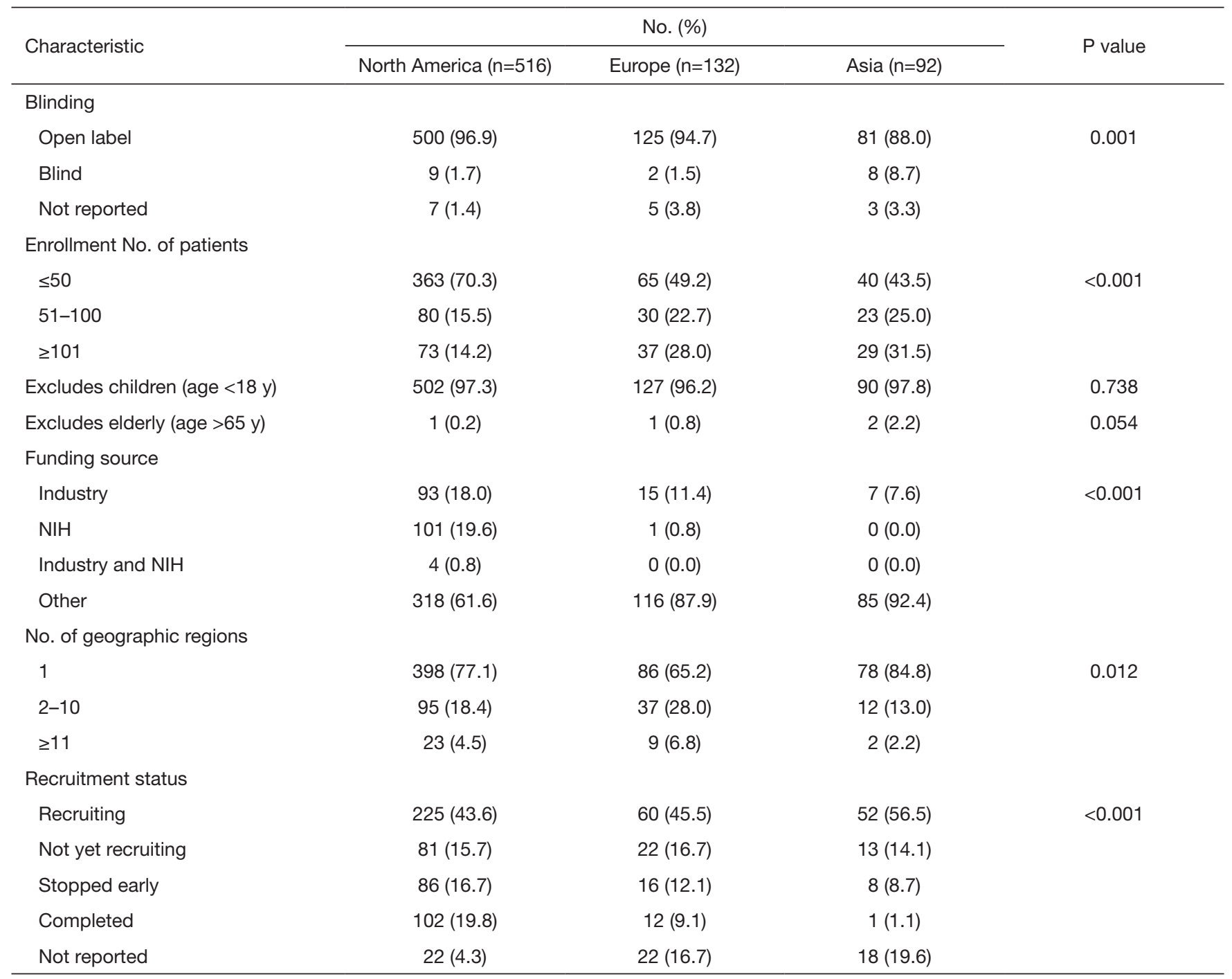

$\mathrm{NIH}$, National Institutes of Health.

ten years. Because stereotactic radiotherapy is a relatively novel technology and develops late in recent years. More than half of stereotactic radiotherapy trials were in the early stage (phase 1 and/or 2), and aimed to add stereotactic radiotherapy to the standard care. More important, there were $119(15.7 \%)$ trials regard to stereotactic radiotherapy combined with immunotherapy, which is a research hotspot in recent years. Many studies have demonstrated that radiotherapy combined with immunotherapy will lead to enhanced antitumor immune responses and improved clinical outcomes $(14,15)$. Furthermore, stereotactic radiotherapy with high doses per fraction is more able to exert an abscopal effect theoretically (16). However, some studies found no improvement in abscopal effect or survival with the addition of SBRT to immune checkpoint inhibitors (17). Hence, more trials are still required to fully understand the efficacy and toxicity of the different radioimmunotherapy combinations (18).

Stereotactic radiotherapy trials registered on ClinicalTrials. gov were small in numbers of participants. Moreover, the majority $(95.0 \%)$ were open-label trials, similarly to prior ClinicalTrials.gov analyses of radiotherapy trials (96.7\%) (19). This result is not surprising, because it is usually not feasible to use blinding in evaluating stereotactic radiotherapy. Even though stereotactic radiotherapy trials were predominantly single arm and nonrandomized. One encouraging note was 
Table 4 Univariate analysis of stereotactic radiotherapy trial characteristics associated with stopped early

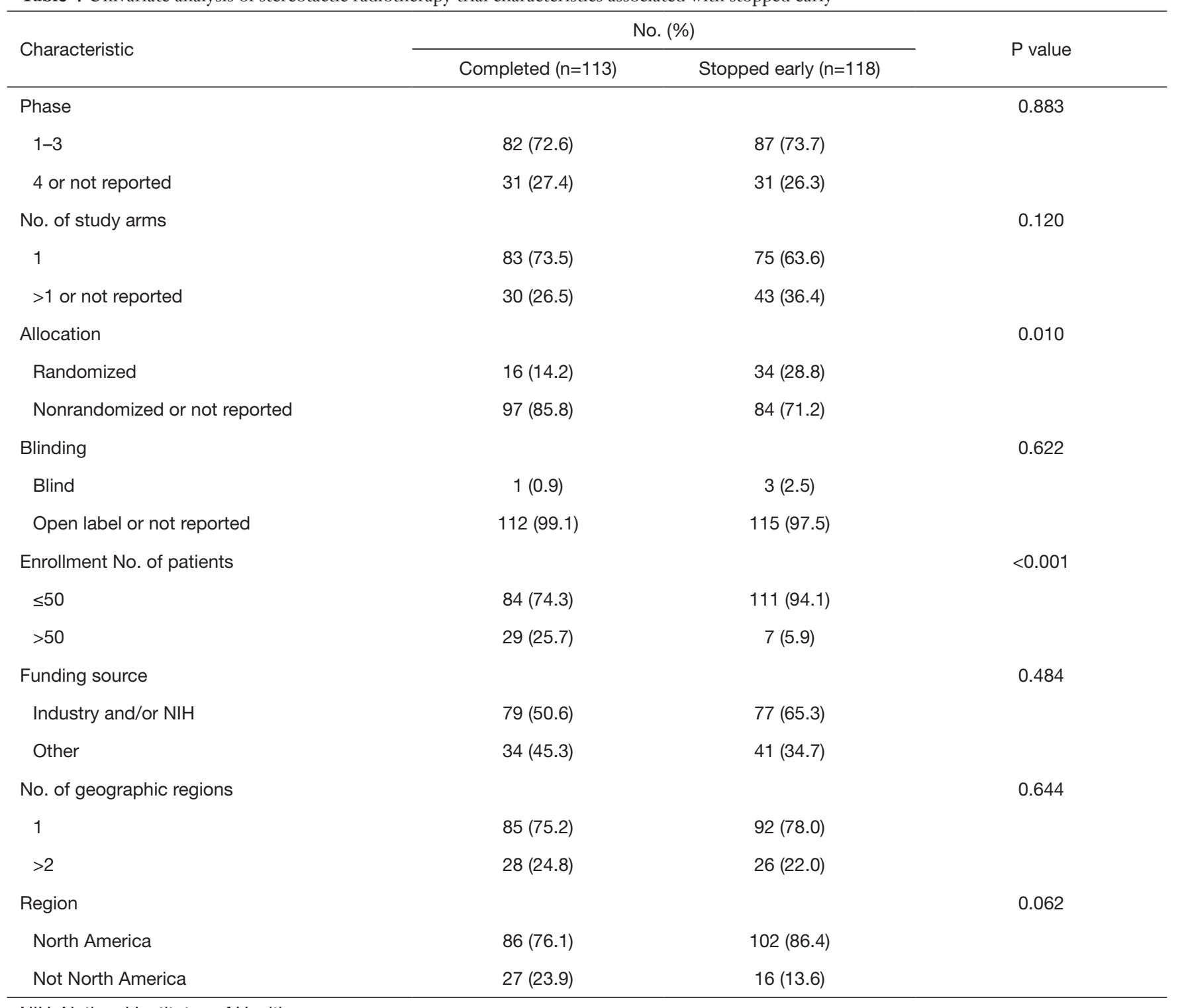

$\mathrm{NIH}$, National Institutes of Health.

Table 5 Multivariate analysis of stereotactic radiotherapy trial characteristics associated with stopped early

\begin{tabular}{lccc}
\hline Characteristic & Beta Coefficient & Odds Ratio (95\% Cl) & P Value \\
\hline Allocation & Reference & Reference \\
Nonrandomized or not reported & 2.091 & $8.090(3.095-21.145)$ \\
Randomized & & Reference \\
Enrollment No. of patients & Reference & $<0.001$ \\
$>50$ & 1.338 & $3.813(1.759-8.267)$ \\
$\leq 50$ & & \\
\hline
\end{tabular}


that the proportion of more than 2 arms and randomized design increased during the 2 periods (2010-2014 and 20152019). Randomized controlled trial (RCT) is the ideal method to test safety and effectiveness of interventions. It can reduce bias of enrolled patients and provide highest evidence (20).

There appeared to be little interest by industry or NIH to support stereotactic radiotherapy trials. However, the proportion of industry-funded trials increased over time. Because industry are usually pharmaceutical companies. With the development of anti-tumor drugs, more stereotactic radiotherapy trials were designed combination with drugs which were funded by industry. Funding sources is related to data sharing after the end of trials. Studies showed that industry-funded trials were less likely to share data (21). While the results of government-funded trials might be published selectively (22). Therefore, it is urgently need to foster closer collaborations among oncologists, industry, government, and other concerned parties. The majority of stereotactic radiotherapy trials were conducted in North America, which reflects the fact that clinicaltrials.gov is a North American register. However, more and more clinical trials were conducted in Asian countries, because of the development of economy and health care in recent years.

Overall, $15.4 \%$ stereotactic radiotherapy trials stopped early, which is more than prior ClinicalTrials.gov analyses of radiotherapy trials (10.1\%) (19). Interestingly, we found that stereotactic radiotherapy trials with randomized allocation or enrollment patients $\leq 50$ were more likely to stop early. A study showed that the reasons for radiotherapy RCT failure were categorized as: lack of accrual $(57.5 \%)$, inadequate funding $(15.0 \%)$, drug unavailability $(7.5 \%)$, interim data monitoring report recommendations $(7.5 \%)$, and other (12.5\%) (23). Some solutions are required to reduce the risk of trial failure. First, increase awareness and educate participant patients about the importance of participation in trials. Second, ensure adequate funding resources. Third, investigators integrate a qualitative intervention into their study design by training research centers and staff.

Two limitations should be considered in interpreting our findings. Firstly, we just searched on clinicaltrials.gov, the stereotactic radiotherapy trials registered on other databases were not included. Secondly, our analysis relied on accurate and complete reporting of all registered information, but missing or inaccuracy data may have complicated the results.

\section{Conclusions}

This overview of trials registered on ClinicalTrials.gov affords a remarkable opportunity to better understand clinical research in stereotactic radiotherapy. Stereotactic radiotherapy trials are predominantly early-phase, small, single arm, nonrandomized and open label. Stereotactic radiotherapy trials with randomized allocation or enrollment patients $\leq 50$ are associated with trials stopped early. Limited resources should be allocated effectively to well-designed trials, thus provide evidence-based medicine for cancer care.

\section{Acknowledgments}

We would like to thank Jiang-Dong Sui for his help in polishing our paper.

Funding: This study was supported by the Science and Technology Research Project of Chongqing Education Commission (KJQN201900104).

\section{Footnote}

Peer Review File: Available at https://dx.doi.org/10.21037/ tcr-21-1189

Conflicts of Interest: All authors have completed the ICMJE uniform disclosure form (available at https://dx.doi. org/10.21037/tcr-21-1189). The authors have no conflicts of interest to declare.

Ethical Statement: The authors are accountable for all aspects of the work in ensuring that questions related to the accuracy or integrity of any part of the work are appropriately investigated and resolved.

Open Access Statement: This is an Open Access article distributed in accordance with the Creative Commons Attribution-NonCommercial-NoDerivs 4.0 International License (CC BY-NC-ND 4.0), which permits the noncommercial replication and distribution of the article with the strict proviso that no changes or edits are made and the original work is properly cited (including links to both the formal publication through the relevant DOI and the license). See: https://creativecommons.org/licenses/by-nc-nd/4.0/.

\section{References}

1. Onderdonk BE, Gutiontov SI, Chmura SJ. The Evolution (and Future) of Stereotactic Body Radiotherapy in the Treatment of Oligometastatic Disease. Hematol Oncol 
Clin North Am 2020;34:307-20.

2. Potters L, Kavanagh B, Galvin JM, et al. American Society for Therapeutic Radiology and Oncology (ASTRO) and American College of Radiology (ACR) practice guideline for the performance of stereotactic body radiation therapy. Int J Radiat Oncol Biol Phys 2010;76:326-32.

3. Wilke L, Andratschke N, Blanck O, et al. ICRU report 91 on prescribing, recording, and reporting of stereotactic treatments with small photon beams : Statement from the DEGRO/DGMP working group stereotactic radiotherapy and radiosurgery. Strahlenther Onkol 2019;195:193-8.

4. Milano MT, Usuki KY, Walter KA, et al. Stereotactic radiosurgery and hypofractionated stereotactic radiotherapy: normal tissue dose constraints of the central nervous system. Cancer Treat Rev 2011;37:567-78.

5. De Angelis C, Drazen JM, Frizelle FA, et al. Clinical trial registration: a statement from the International Committee of Medical Journal Editors. N Engl J Med 2004;351:1250-1.

6. Food and Drug Administration Amendments Act (FDAAA) of 2007. Accessed February 14, 2020. Available online: https://www.fda.gov/regulatory-information/selectedamendments-fdc-act/food-and-drug-administrationamendments-act-fdaaa-2007

7. ClinicalTrials.gov. US National Institutes of Health. Accessed April 1, 2020. Available online: https:// clinicaltrials.gov

8. Institute of Medicine (US) Committee on Cancer Clinical Trials and the NCI Cooperative Group Program, Nass SJ, Moses HL, Mendelsohn J. editors. A National Cancer Clinical Trials System for the 21st Century: Reinvigorating the NCI Cooperative Group Program. Washington (DC): National Academies Press (US); 2010.

9. Young RC. Cancer clinical trials--a chronic but curable crisis. N Engl J Med 2010;363:306-9.

10. Palma DA, Olson R, Harrow S, et al. Stereotactic ablative radiotherapy versus standard of care palliative treatment in patients with oligometastatic cancers (SABRCOMET): a randomised, phase 2, open-label trial. Lancet 2019;393:2051-8.

11. Paix A, Noel G, Falcoz PE, et al. Cost-effectiveness analysis of stereotactic body radiotherapy and surgery for medically operable early stage non small cell lung cancer. Radiother Oncol 2018;128:534-40.

12. Bujold A, Massey CA, Kim JJ, et al. Sequential phase I and II trials of stereotactic body radiotherapy for locally advanced hepatocellular carcinoma. J Clin Oncol
2013;31:1631-9.

13. Siva S, Bressel M, Murphy DG, et al. Stereotactic Abative Body Radiotherapy (SABR) for Oligometastatic Prostate Cancer: A Prospective Clinical Trial. Eur Urol 2018;74:455-62.

14. Antonia SJ, Villegas A, Daniel D, et al. Overall Survival with Durvalumab after Chemoradiotherapy in Stage III NSCLC. N Engl J Med 2018;379:2342-50.

15. Grimaldi AM, Simeone E, Giannarelli D, et al. Abscopal effects of radiotherapy on advanced melanoma patients who progressed after ipilimumab immunotherapy. Oncoimmunology 2014;3:e28780.

16. Finkelstein SE, Timmerman R, McBride WH, et al. The confluence of stereotactic ablative radiotherapy and tumor immunology. Clin Dev Immunol 2011;2011:439752.

17. McBride S, Sherman E, Tsai CJ, et al. Randomized Phase II Trial of Nivolumab With Stereotactic Body Radiotherapy Versus Nivolumab Alone in Metastatic Head and Neck Squamous Cell Carcinoma. J Clin Oncol 2021;39:30-7.

18. Herrera FG, Bourhis J, Coukos G. Radiotherapy combination opportunities leveraging immunity for the next oncology practice. CA Cancer J Clin 2017;67:65-85.

19. Liu X, Zhang Y, Tang LL, et al. Characteristics of Radiotherapy Trials Compared With Other Oncological Clinical Trials in the Past 10 Years. JAMA Oncol 2018;4:1073-9.

20. Sniderman AD, LaChapelle KJ, Rachon NA, et al. The necessity for clinical reasoning in the era of evidence-based medicine. Mayo Clin Proc 2013;88:1108-14.

21. Saito H, Gill CJ. How frequently do the results from completed US clinical trials enter the public domain?--A statistical analysis of the ClinicalTrials.gov database. PLoS One 2014;9:e101826.

22. Ross JS, Mulvey GK, Hines EM, et al. Trial publication after registration in ClinicalTrials.Gov: a cross-sectional analysis. PLoS Med 2009;6:e1000144.

23. Nguyen TK, Nguyen EK, Warner A, et al. Failed Randomized Clinical Trials in Radiation Oncology: What Can We Learn? Int J Radiat Oncol Biol Phys 2018;101:1018-24.

Cite this article as: Zhang X, Yang DY, Wang C, Huang L. Characteristics of stereotactic radiotherapy clinical trials registered on ClinicalTrials.gov. Transl Cancer Res 2021;10(10):4316-4326. doi: 10.21037/tcr-21-1189 